\title{
Benchmarking service delivery for sports tourism and events: Lessons for Gorski Kotar, Croatia from Pokljuka, Slovenia
}

\author{
Nicholas Wise ${ }^{1 *}$, Marko Perić ${ }^{2}$ and Jelena Đurkin ${ }^{3}$
}

Received: 02/06/2018 Accepted: 03/04/2019

\begin{abstract}
${ }^{1}$ Liverpool John Moores University, Faculty of Education, Health and Community, Liverpool L17 6BD, UK, Email: n.a.wise@ljmu.ac.uk; Tel.: +44(0)151-231-4601

2 University of Rijeka, Faculty of Tourism and Hospitality Management, Primorska 42, 51410 Opatija, Croatia. E-mail: markop@fthm.hr

${ }^{3}$ University of Rijeka, Faculty of Tourism and Hospitality Management, Primorska 42, 51410 Opatija, Croatia. E-mail: jelenad@fthm.hr

* Corresponding author
\end{abstract}

Coordinating editor: Stanislav Ivanov

\begin{abstract}
Benchmarking is essential for developing destinations to improve and develop their service delivery. Croatia is a well-established summer tourism destination, but more remote (inland) destinations seek to increase their competitiveness to help sustain Croatian tourism year-round-to diversify tourism offerings beyond the (more traditional) sea and sun opportunities. Expanding Croatia's tourism offer will require additional investments, not only in coastal destinations but in rural continental areas as well. Looking at how more established rural and winter destinations are planned and managed, this paper seeks to discuss how Croatia can learn from its neighbour Slovenia which has well-established winter sports destinations (in rural areas). This is where a benchmarking approach, building on a comparative analysis conducted through fieldwork research contributes new insight. Research was conducted in both Pokljuka (Slovenia) and Gorski kotar (Croatia) between 2015 and 2017. Three different procedures were used to collect data: (1) documental research of the destinations, facilities and events, (2) on site visits involving qualitative interviews and conversations with key stakeholders and (3) direct observation of the destination while attending events. Three emergent themes best reflected the analysed insights from the data collection: infrastructure, business operations and community involvement/stakeholder participation. To assess different points of service offering and delivery, discussions in Pokljuka were framed around sports tourism opportunities and their established business models to understand planning, management, organisation and service delivery. These same three points are then discussed as opportunities for Gorski kotar. To reiterate the benchmarking focus, first research must present a comparative analysis and then put emphasis on planning and managing service delivery to help highlight how insight from a well-established destination informs emerging destinations with tourism potential.
\end{abstract}

Keywords: Destination Benchmarking; Sports Tourism; Service Delivery; Croatia; Slovenia

Citation: Wise, N., M. Perić and J. Đurkin (2019) Benchmarking service delivery for sports tourism and events: Lessons for Gorski Kotar, Croatia from Pokljuka, Slovenia. European Journal of Tourism Research 22, pp. 107-128

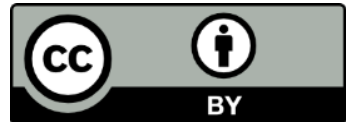

RESEARCH PAPER
This work is licensed under the Creative Commons Attribution 4.0 International (CC BY 4.0). To view a copy of this license, visit https://creativecommons.org/licenses/by/4.0/ 


\section{Introduction}

Benchmarking is used in business studies and across a range of disciplines (including tourism) to evaluate and compare practices based on an industry standard (Moriarty, 2011). While the aim of benchmarking is to adopt best practices based on industry demands and standards, this can prove difficult in emerging tourism destinations because such an industry relies on a range of stakeholders and a place is dependent upon various factors such as funding, involvement of the community, quality of infrastructure and the natural environment. Research has highlighted that benchmarking is a systematic approach used to develop strategy (Xiang et al., 2007), but as this paper argues, lessons from how an established destination approaches service delivery needs addressed and critically evaluated in a developing destination. This points to the need for comparison and analyses conducted through fieldwork and direct interaction with destination stakeholders. Such research allows academics to transfer knowledge to enhance management and planning practices to enhance service delivery, and the researchers are the ones who enable access and a platform to disseminate results between other researchers and stakeholders.

The aim of this paper is to conduct an analysis of two destinations, one established and one developing to frame the need for a benchmarking approach to develop a set of recommendations for the emerging destination. Assessing sports tourism delivery in a wellestablished destination and taking elements of good practice will lead to suggestions and recommendations for a developing tourism destination in a related environment with similar resources. In other words, this paper seeks to discuss how Croatia can learn from its neighbour Slovenia which has well-established winter sports destinations (in rural areas). We consider the 'rural' as well because this paper draws from cases in more remote mountainous areas, as this is in line with attempts and national tourism strategies to further diversify Croatia's tourism offering beyond the coastal destinations. Croatia is regarded as a competitive summer destination, with extensive sea and sun opportunities that have brought much investment and development to the country's coast, but problems persist in more remote inland destinations that have valuable natural resources but largely remain underdeveloped, or lack strategic planning and management agendas aimed at competitive service delivery.

This paper is not meant to be a direct comparison of Slovenia and Croatia, which would be difficult since Slovenia's mountainous areas are Alpine. However, an emphasis on planning, service delivery and community involvement in Slovenia offers useful insight for destinations such as Gorski kotar in Croatia to consider for improving their sports tourism offer. Instead, this paper acknowledges insight from the literature on destination benchmarking, tourism service delivery, destination management and community involvement to argue for the need to conduct research in related destinations (or case sites) so good practice can be considered and adopted in emerging destinations, proved beneficial in previous research (e.g. João Carneiro, Breda \& Cordeiro, 2016; Mulec \& Wise, 2013; Oses, Gerrikagoitia \& Alzua, 2016; Reid, 2011). While case-studies are important when gathering data, and they relate to a specific research focus, it is the points of comparison and recommendations that emerge guided by the academic literature to present how such work contributes to the wider body of tourism literature. Moreover, such work offers practical evidence that local managers and planners can consider to develop their destinations. The usefulness of comparative analysis and benchmarking research is to have an impact on service delivery and organisational improvement locally (see Luštický \& Bína, 2014; Müller \& Berger, 2012).

The next section will address the importance of destination benchmarking before presenting insight on the need for such research in Croatia. This is followed by an outline of the methods/approach to data collection before presenting the results from field visits, observations and interviews/conversations in Pokljuka, Slovenia and Gorski kotar, Croatia. The results focus on infrastructure, business operations and community involvement/ stakeholder participation so to offer insight on sports tourism planning, service delivery and 
operations, looking at practices in Pokljuka to inform Gorski kotar-presenting Pokljuka as an established benchmark. The conclusion will outline future research directions and the need to continually benchmark destinations so that changes and approaches in Gorski kotar contribute to a sustainable development trajectory and service offering and delivery is in line with changing industry trends, demands and established good practice.

\section{Destination Benchmarking}

Much tourism related research has addressed conceptualisations, approaches and strategic directions of destination benchmarking research (see Fuchs, Peters \& Weiermair, 2002; Khazai, Mahdavian \& Platt, 2018; Kozak, 2002; Kozak, 2004; Kozak \& Baloglu, 2011; Luštický \& Bína, 2014; Oses et al., 2016; Pike, 2017; Sainaghi \& Baggio, 2017; Xiang et al., 2007). Benchmarking is a key measurement of business performance and checking competitive strengths and areas of improvement (Boxwell, 1994; Camp, 2006).

In the field of tourism management, benchmarking is key in developing a competitive (and sustainable) destination (see Blancas et al., 2018; Fuchs et al., 2002; Kozak, 2002), especially among emerging or underdeveloped destinations that have much to learn from wellestablished destinations (Kozak, 2003; Müller \& Berger, 2012). In addition, destinations seeking to recover from negative images or tragic events use benchmarking (Khazai et al., 2018) or to compare approaches undertaken by different destinations (Wise, 2011). Kozak's (2002) seminal work on destination benchmarking points to the need for seeking findings based on similar insight, operations and strategies in related destinations. Building on Kozak (2002), Oses et al. (2016, p. 48) argue "monitoring the performance of a destination is essential for effective destination management." Thus, when weaknesses are identified it is important to look to best case (established) destinations to inform future service improvements. Benchmarking to some is monitoring and evaluating performance (Oses et al., 2016), with indicators framed around cultural, social, economic, political and environmental impacts (Fuchs et al., 2002; Kozak, 2002; Spirou, 2011; Wise, 2016).
Moreover, benchmarking is important because it allows destinations to check their status or progress and recognize their competitiveness as a destination can identify existing strengths and weaknesses in relation to similar destinations (see Boxwell, 1994; Camp, 2006; Kozak, 2002; Kozak \& Baloglu, 2011; Pike, 2017; Mulec \& Wise, 2013).

According to Xiang et al. (2007, p.81) "benchmarking has been studied as a tool for comparatively evaluating the performance of tourist destinations." Much benchmarking research and consideration looks solely at the development of destinations and existing infrastructures, common in competitiveness research (see Caber, Albayrak \& Matzler, 2012), but there is a need to assess organisation strategy as well because there are a few issues surrounding the planning, participation and community involvement in the development of destinations (Luštický \& Bína, 2014; Xiang et al., 2007). Organisational strategy is linked to operations, and Blancas et al. (2018) devise a strategy of goal planning to focus on more operational approaches that put emphasis on setting goals and targets to ensure sustainability is achieved and maintained. This is something that this paper considers because it is essential that we understand the delivery of tourism in destinations beyond the facilities and infrastructures. Resources are key and vary from place to place, but it is essential that we are comparing destinations with similar natural resources as we need to assess delivery techniques and mobilisation of the community, despite and beyond what physical infrastructures exist, so insight on strategy, organisation and delivery techniques is necessary to suggest solutions.

Xiang et al. (2007) also argue that benchmarking needs to be continuous because service delivery needs to change/adapt to consumer demand, and therefore strategies need to be checked, updated and amended. It is further noted that familiarity and perception are important in sustaining a competitive destination (Herrero et al., 2017). Many organisations tend to develop strategic plans every five years to check up on industry standards and current benchmarks to realise 
potential strengths and weaknesses (Wise, Aquilino \& Armenski, 2018). For instance, universities use subject benchmarks to ensure courses being delivered are meeting industry demands/needs. This is also necessary in tourism to continually check the temporality of a destination's offering, based on planning, organisation and participation, along with necessary resources to maintain competitiveness and adapt to change accordingly (Pike, 2017; Sainaghi \& Baggio, 2017). Pike (2017, p. 126) notes "a destination's market position will change positively only slowly over time" and a destinations market positioning means that researchers need to try and adequately understand strengths and weaknesses in comparison to similar destination products (Wise, Aquilino \& Armenski, 2018). Luštický and Bína (2014) add that while we put much emphasis on recognising weaknesses, when evaluating strengths, it is important to evaluate how quality reinforces strengths in wellestablished destinations.

Cernata and Gourdon (2012) are concerned with benchmarking sustainable tourism, and they consider economic, socio-ecologic and infrastructures as dimensions, arguing the need to assess both tangible and intangible indicators, relating to Xiang et al. (2017) who would argue intangibles can help us understand organisational dimensions. Holistically, these features connect our understanding of benchmarking alongside competitiveness. It has been noted that the competitiveness of a destination lies mainly in its capacity to preserve its position among similar markets alongside the range of factors and variables (Armenski et al., 2012; Domínguez, Darcy \& Alén González, 2015; Kozak, 2004; Mulec \& Wise, 2013). But beyond these external factors and forces, key to organisational dimensions in any field of tourism is linking to planning agendas, participation of stakeholders and involvement of the local community (Perić, Wise \& Dragičević, 2017; Perić \& Wise, 2015; Warburton, 2009; Wise, Mulec \& Armenski, 2017). Furthermore, benchmarking can help shape tourism planning practices locally to improve destination structures, delivery and management, as well as seeking an understanding about how to engage the local community (see Gajdošík et al., 2017).

Community engagement and level of involvement in tourism-related activities is very important for sustainable tourism development, especially in rural areas (Quaranta, Citro \& Salvia, 2016). Community members can be participants, spectators or volunteers at various tourism/sport events, and local businesses are important links in the chain of local tourism offer (Reid, 2011; Đurkin \& Wise, 2018; Wise \& Harris, 2017). As tourism benefits from community involvement, the local community can also have various important (non-financial) benefits from engaging in tourism. Participation and involvement in event organisation and volunteering in local initiatives (including sport activities) can support the empowerment and capacity of residents (Diamond, 2008; Wise \& Perić, 2017). However, community involvement cannot be easily benchmarked since it is a product of local social capital, human capital and cultural, historical, geographical, political and other circumstances of a certain area. Nevertheless, it should be considered when examining good practice examples of destinations with quality tourism offer.

\section{Research Field: The Cases of Croatia and Slovenia}

In last few years Croatia recorded a huge tourist "boom" with the total number of tourist arrivals as well as the overnight stays between 2011 and 2017 seeing continual increases. Official data suggest that in 201717.4 million tourists arrived in Croatia (Ministry of Tourism, 2018). This represents a $12.7 \%$ increase compared to the previous year (2016) and a $52.6 \%$ increase compared to 2011 (Ministry of Tourism, 2018). A total of 86.2 million overnight stays was a $10.6 \%$ increase from 2016 and a $42.7 \%$ increase since 2011 (Ministry of Tourism, 2018). However, it is important to highlight that $86 \%$ of this demand refers to summer months (i.e. the period from June to September), and this seasonality is by far the highest in relation to all other countries across the entire Mediterranean. While Croatia is a well-established summer tourism destination, to increase its competitiveness and to sustain the destination year-round, the country is seeking opportunities to diversify its tourism offering 
beyond the (more traditional) summer sea and sun opportunities (Government of the Republic of Croatia, 2013). Expanding Croatia's tourism offer will require additional investments, not only in coastal destinations but in continental (and rural) areas as well.

To this regard, based on the purpose of this paper, winter sports tourism is a desired direction in regions such as Gorski kotar, Croatia. Gorski kotar is a mountainous area in the north of Croatia situated between two of Croatia's larger cities, the capital of Zagreb and the coastal city of Rijeka. It is one of the most protected areas in Croatia, with Risnjak National Park covering most of the region. It is further characterised by abundant mountainous natural resources making it an ideal region to develop a vast number of leisure, sport and tourism activities year-round: summer (mountaineering and hiking, cycling, sport fishing) and winter (sledding, cross-country skiing, biathlon, ice skating).

Regarding winter activities, the medium-high mountainous environment, lack of quality infrastructure and a lack of abundant snow due to warmer winter temperatures do not allow extensive alpine skiing facilities-but is ideal for the sports mentioned because they require less snow (Perić, Škorić \& Jurčević, 2016). However, when it comes to the overall tourism economy, Gorski kotar is an example of a lessdeveloped destination in Croatia, and with only 23,011 inhabitants in an area of $1,275.05 \mathrm{~km}^{2}$, and the whole region is suffering from depopulation (Croatian Bureau of Statistics, 2013). Given its geographic position, there is much to gain from more established rural alpine destinations where the winter sports tourism and events offer are established and well sustained, especially in the country's rural areas.

Neighbouring Slovenia is a developed alpine destination. For the fourth consecutive year Slovenia recorded growth in tourist arrivals and overnight stays. In 2017 official statistical data registered more than 4.9 million tourist arrivals and 12.6 million overnight stays representing an increase in arrivals by $14.6 \%$ and in overnight stays by $12.6 \%$ when compared to 2016 (Slovenian Tourist Board, 2018).
Although the overall numbers are lower than in Croatia, for this paper is relevant that only $44 \%$ of this demand refers to summer months (Slovenia has short coastal line and therefore only a few coastal resorts), $19 \%$ to spring, $21 \%$ to autumn and $16 \%$ to winter. In addition, most accommodation facilities in Slovenia are Alpine, and account for $34 \%$ of tourist arrivals and $32 \%$ of overnight stays in Slovenia. The number of tourist arrivals and overnight stays of foreign visitors in Alpine Slovenia increased by more than $20 \%$ compared to 2016 . Besides the nation's capital, Ljubljana, mountain resorts and health resorts make the core of the Slovenian tourist offer. Pokljuka (home of the International Biathlon Union World Cup Biathlon (WCB) race) is an example of popular inland destination which provides services during the winter and summer season, and a true benchmark for Gorski kotar and Croatia.

\section{Data Collection and Analysis: Site Visits, Interviews and Conversations}

Benchmarking research is about identifying an organisation (or in this case a destination) that has a problem or weakness that needs addressed or developed further so to better perform based on relevant and comparative measures (Kozak, 2004). From a destination perspective then, a case study approach was useful for this study given the planning and managing contexts (Yin, 2009), which were deemed necessary to investigate in Pokljuka, Slovenia to offer recommendations for Gorski kotar, Croatia. According to Yin (2009) a case study approach is appropriate when the boundaries between the phenomenon and its context are blurred. In addition, case study research allows for the possibility of using multiple data sources which can also enhance comparisons and interpretations of data gathered (Patton, 1990; Yin, 2009). Fieldwork in both Pokljuka (Slovenia) and Gorski kotar (Croatia) was conducted between 2015 and 2017 and comprised three different procedures regarding data collection: (1) documental research of the destinations, facilities and events, (2) on site visits involving qualitative interviews and conversations with key stakeholders and (3) direct observation of the destination while attending events. 
Foremost, to gather general context on these destinations and their tourism offer, the authors conducted an extensive documental research publicly available on the Internet. More precisely, considering the growing importance of the internet concerning tourism information searches (e.g. Buhalis \& Laws, 2001; Lundmark \& Muller, 2010; Perić, Škorić \& Jurčević, 2016), the authors focused on local tourist organisations and main service provider websites, including event organisers and hospitality firms. In total, 87 pages were gathered and analysed.

Second, qualitative data on the winter and rural sports tourism offer was collected through interviews and conversations with key stakeholders and participant observations in both Pokljuka and Gorski kotar. Three site visits were made to Pokljuka and regular site visits were made to Gorski kotar to discuss planning/managing operations and service delivery to gain insight based on these welland less-established destinations, respectively. Regarding Pokljuka, the first trip was dedicated solely to meeting with the managing director of the Centre Pokljuka, a firm responsible for hospitality and the sporting facility. Subsequent visits were also made to observe events $\left(27^{\text {th }}\right.$ Pokljuka Marathon and $3^{\text {rd }}$ No Border Cup) and speak with event organisers.

Regarding research in Gorski kotar, the authors visited nine local tourism board directors in Gorski kotar (in the three towns and six municipalities). One visit was made to observe simultaneous cross-country skiing events (at the Mrkopalj Peace Memorial) and speak with two event organisers. The purpose of these visits was to discuss and observe the sports tourism offer and collect data on related projects (see Perić, Škorić \& Jurčević, 2016; Perić, Đurkin \& Wise, 2016; Perić, Čuić Tanković \& Đurkin, 2017).

In total, 14 in-depth semi-structured qualitative interviews with key informants (three in Pokljuka and 11 in Gorski kotar) were conducted. Interviews and conversations included similar core questions to gain deeper perspectives from those immediately involved in planning, organising and sports tourism service delivery as well as discussions on how
Pokljuka can be a useful benchmark to improve planning, managing, operations and delivery in Gorski kotar. Two authors were always present during each interview to take and confirm notes. Each interview lasted on average 60 minutes (from minimum 45 to maximum 90 minutes). The interviews helped to inform the development of themes below in the analysis and frame insight addressed and incorporated below.

Finally, as mentioned above, the researchers also spent time in Pokljuka observing operations during two sporting events to help better understand planning and managing operations during events, for both the sporting participants and the tourists in attendance at this benchmark case in Slovenia. One event is also observed in Gorski kotar. Due to length of the races, observations were made at the opening ceremony, awards ceremonies, the start/finish areas of the races, and part of the course route. The authors recorded their field notes during observations at events and all site visits. During all three events (two in Pokljuka and one in Gorski kotar), several casual conversations with other stakeholders were conducted (and noted), including locals working/volunteering at the event and people attending events, which added supplemental insight.

Observational approaches in the field in management studies help familiarise researchers with relevant practices, so that they can collect field notes, identify strengths and weaknesses and bring in critical reflection to relate to or refer when discussing findings and developing recommendations (Woodside, 2016). Interviews/conversations complement observations/site visits and recorded observations from site visits help inform questions that stakeholders, participants and attendees were asked. In this study, supplemental knowledge was gained through conversations on site while making observations during events. Interviews and conversations allow the researcher to address and evaluate contrasting perspectives and approaches in management and operations research (Woodside, 2016). Subsequently, interviews and conversations allow researchers to obtain primary data not available elsewhere 
providing depth into how and why certain planning measures and operations are carried out in a particular manner (Chase, 2011). Likewise, observations allowed the researchers to collect photographs to show how spaces are utilised and organised. Photographs were collected at events and during site visits when interviews/conversations were being held to record and help explain both event and landscape features.

All data were inductively coded, more precisely, strategies of memoing, coding and comparative methods provided the guiding principles for analysis (see Charmaz, 2006; Levy, 2015). From a social sciences perspective, Harris (2006) notes inductive research is about discovery-to find out more about how and why a particular social world is as it is, and this is especially relevant in planning and managing research because researchers need to evaluate approaches useful for understanding service delivery. Initial/open coding using exact words from gathered data without applying preexisting categories to the data was the first stage of analysis (Charmaz, 2006). Initial codes have been altered and refined during this phase. In the next stage, focused coding was done involving identification of the most frequent, significant and conceptual coding (Charmaz, 2006). Starting from making decisions about which initial codes make the most analytic sense to categorisation, data fractured during initial phase were reassembled, categorisations were then reframed, and relationships between categories were highlighted (Charmaz, 2006; Levy, 2015).

The authors worked independently on analysing and classifying the collected material and then they jointly discussed and agreed on the results. To ensure trustworthiness of the data, participants were given the opportunity to review their contributions. After the interviews and conversations, participants are asked if they would like to take part in memberchecking to validate the data collected, and then, according to Creswell (2012), a summary of the interview was sent to participants via email to confirm notes and interpretations. No one indicated any concerns with the developed themes, so this validated the data. Finally, categories and subcategories were woven into a story line under each of the identified core categories embedded throughout the data.

The following section outlines lessons from Pokljuka based on the field notes and conversations held while visiting the site and events. To protect the identity of the individuals, no direct quotes or names will be used but instead observations and reflections on what was observed and discussed will frame the insight gained from Pokljuka, Slovenia as a benchmark case to support the case of Gorski kotar, Croatia.

\section{Analysis: Lessons from Pokljuka}

Insight on sports tourism planning, service delivery and operations are considered here in the analysis of this paper. Three emergent themes best reflected the analysed insights from the data collection: infrastructure, business operations and community involvement/stakeholder participation. To assess different points of service offering and delivery, discussions in Pokljuka were framed around sports tourism opportunities and their established business models to understand planning, management, organisation and service delivery. These same three points are then discussed as opportunities for Gorski kotar, in line with the focus on benchmarking in this paper.

\section{Infrastructure}

In Slovenia, Pokljuka is a renowned location for cross-country skiing and the centre for biathlon. The site has organised networks. Before 1991 the area was owned by the Yugoslavian army and is currently a NATO base centre for training excellence (for fighting in high mountainous areas). The infrastructure is wellestablished and maintained by the Slovenian Government. With the support of European funds, in 2007, a decision was made to build a centre that would be useful for both military training and sporting events.

As an events venue, the funding from the state allowed the Ski Federation to expand the track and facilities to accommodate athletes and guests. Biathlon plays a significant role in military and police training, and the spaces in Pokljuka are organised around the viewing area where participants gather and complete the course (see Figure 1). Moreover, funding 
allowed for the construction of a centre for biathlon $(€ 4.5$ million from the European Commission, $€ 1.5$ million from the Ministry of Science, Education and Sport, and $€ 1.1$ million from Slovenia, the Slovenian Ski federation got an additional loan of $€ 3$ million). With the funding to invest in the venue area and centre, the management and operations are carried out by the Special Vehicle Enterprise Centre Pokljuka, a Limited Enterprise who operate independently but are owned by the Slovenian skiing federation. Their aim is to offer and maintain the best biathlon and cross-country infrastructure in the winter (and summer, with participants using wheels) so that the venue and space can be managed year-round. The base of where participants can stay is also close to Triglav, the highest mountain peak in Slovenia and an important area for hiking and climbing, so when events are not taking place, they can sell the room space to leisure and nature enthusiasts.

The success of Pokljuka is the capacity to which they operate. Given the popularity of Pokljuka, and given the scale of such events, there is only one hotel with 33 rooms with 66 beds (additional beds are brought in when events are organised for school groups- groups of children can yield over 100 kids) on site (see Figure 2). There is one apartment in the hotel used to house staff who may need to stay on site, but if rooms are overbooked, they will use the apartment for guests. There is another independently owned hotel a few kilometres away (Šport Hotel Pokljuka), and then a bit farther, but within proximity, there are numerous hotels in the Bled region/valley. Hotels are an important infrastructure in rural areas and investing in hotels in such rural locales can be risky. But when there are established venues, regular events and high demands for a product such as the case in Pokljuka, a hotel investment is financially viable, and can operate to meet and maintain consumer demand.

To expand operations due to the success and exposure, the local project planning facility in Pokljuka are working for the International Biathlon Union (IBU), who are proposing new infrastructures and hotels to accommodate increased capacity, but because this is a National Park with strict environmental regulations the area is closed to expansive developments. Other limitations halting expansion (under the control of the European commission) are regulations on building

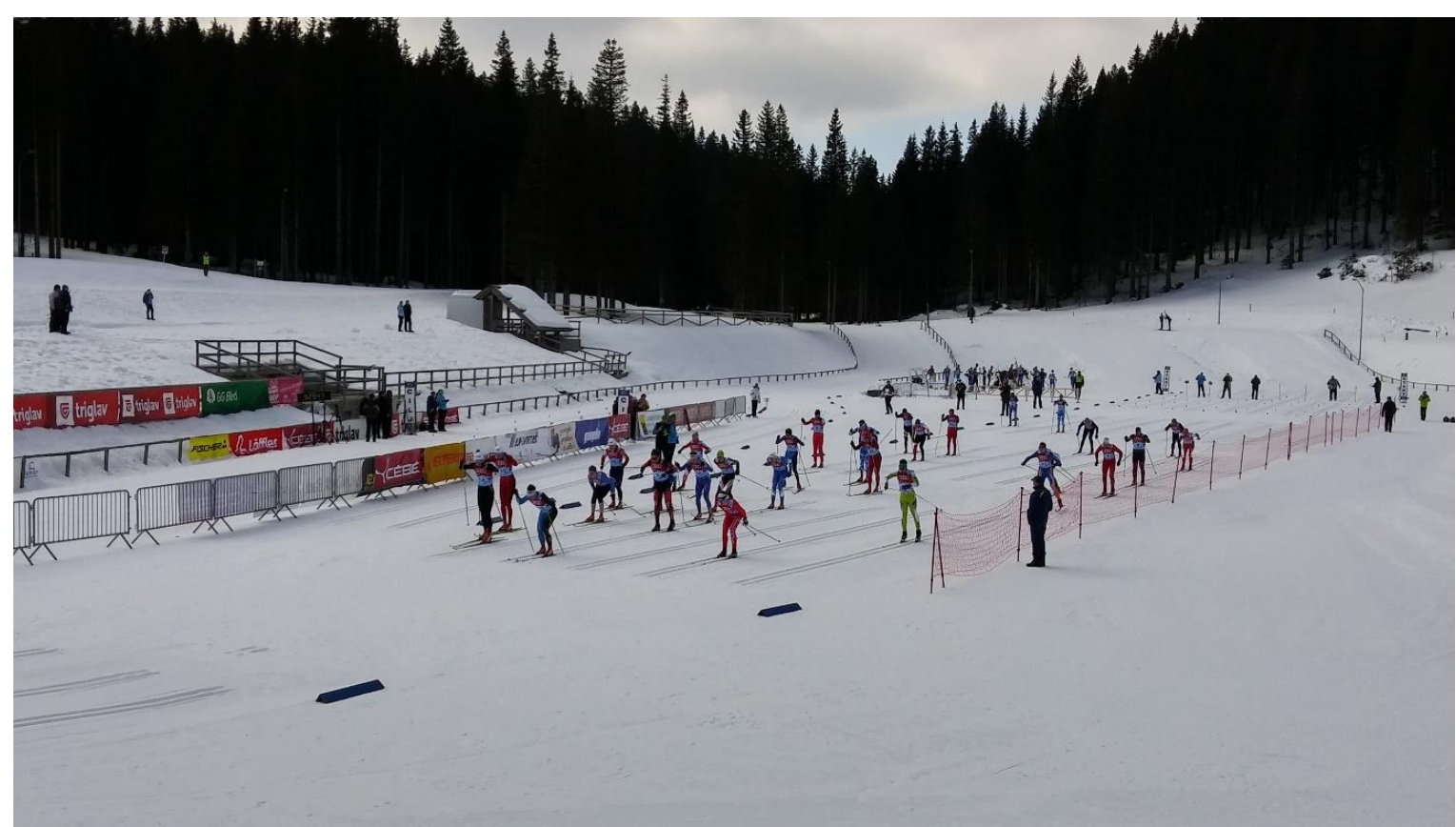

Figure 1. Starting line at the No Border Cup (Photograph taken by $2^{\text {nd }}$ Author) 


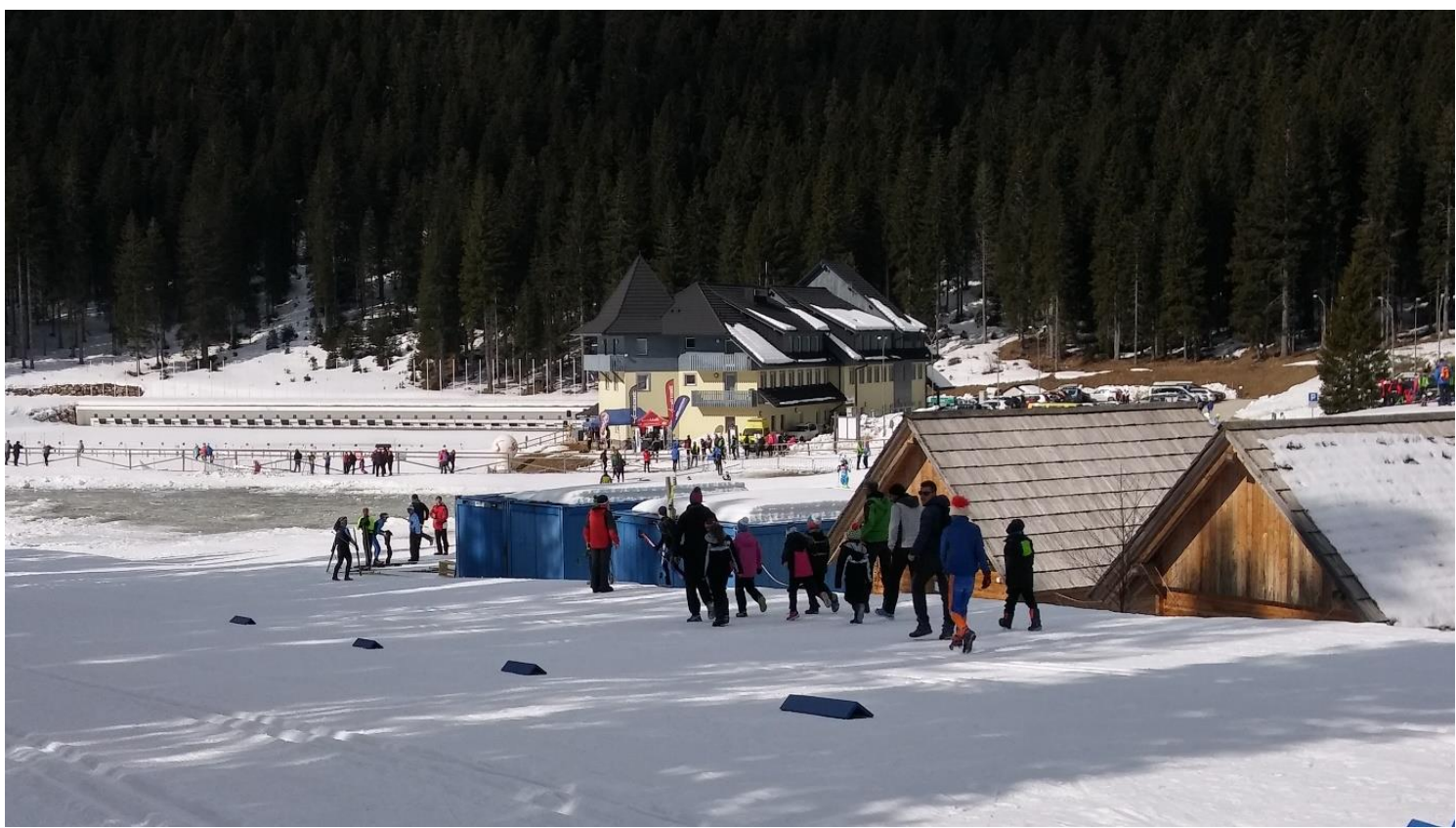

Figure 2. Spectators and participants making their way along the racetrack back to the hotel and parking area (photograph taken by $2^{\text {nd }}$ Author)

façades, amount of lighting, wild animal protection and the need to monitor behaviour (including noise and lighting, so this includes no activities after 8pm). For events in the winter, due to snow cover, there is a $6.5 \mathrm{~km}$ track, and in the summer they only open $1.5 \mathrm{~km}$ of the track that is covered by asphalt (so grass areas are not eroded, and ecosystems not disrupted). For leisurely activity and nature enthusiasts, there are $21 \mathrm{~km}$ of tracks in the area that are maintained by Centre Pokljuka, and there are another $21 \mathrm{~km}$ maintained with the assistance of local tourism organisations.

\section{Business Operations}

The managing director noted that from the midOctober to early-April and mid-May to the end of September distinguish the winter and summer offerings, respectively. There is some down time to maintain the facilities and switch from winter-summer, summer-winter programmes. The peak months are July to August and December to March, and during these months the centre and accommodation spaces are at $100 \%$ (or just under full) capacity. The centre's managing director noted that $60 \%$ of the capacity for the following year is known as to whom it will be sold to, solely based on teams scheduled training and events.
In the ten and a half months of operation, overbookings of $40-50 \%$ are common, and in such instances, they collaborate with other hotel facilities within proximate distance to accommodate the extra demand (mentioned above). Extra demand is common during events because of spectators and other passive participants.

Benchmarking also involves knowing how to price services and offers, so that a destination does not under-charge, or over-charge because they need to maintain a competitive advantage. Prices were not disclosed to us because they are based on pre-existing agreements, length of stay and services required. Given the reputation of Pokljuka and the events offering, they regularly attract teams from Russia, Ukraine, Czech Republic, Belarus, Austria, and across the Balkans. The pricing policy is different based on requests, but the Slovenian teams have a special price because the federation owns this area (and their costs are set to cover operational service delivery costs only and no extra profit is earned). At the centre in Pokljuka, they cater to the needs and demands of the different teams. They also offer specialised medical treatments in the hotel-which includes a sauna and fitness 
room for training indoors. The managing director noted that many teams bring their own doctors and physical therapists, who work with specialists in Koper (a coastal city in Slovenia), but they do their best to cater to each team based on particular needs.

Given the scale of the operation, the centre in Pokljuka only has 11 regular employees (3 for maintenance of the site and area, 2 for cleaning, 3 cooks, 2 receptionists and 1 director). Whilst marketing is an important component of business operations, Pokljuka does not employ any specialists, and any promotions and details of upcoming events, activities and opportunities is done online. The director notes that the sport itself attracts people who have an interest in cross-country skiing and biathlon to the destination, and the location is synonymous with the product. Therefore, they do not struggle to attract business for training in Pokljuka because of the BMW IBU World Cup Biathlon (WCB) (as a key event). The history of the area is also enough to sell the destination. The destination thus sells based on reputation alone (highlighted as the best marketing tool).

Pokljuka also benefits because the WCB is broadcast live on Eurosport, allowing the destination to build a popular and attractive image through media exposure. During the WCB event they attract 9,000 to 10,000 spectators (mostly one-day visitors). The IBU sells special packages, for instance Germans and Norwegians spend $€ 400$ to observe one competition and during the WCB they sell the hotel to the organising committee. Committee members and the best athletes from each country stay in this hotel, and $50 \%$ of all revenues come from the WCB in 10 days (because of higher prices for nightly rates, food and beverages paid by the organising committee).

The sporting calendar in Pokljuka is highlighted by the WCB, but more regular occurrences include active weekends (this has been developed with the Slovenian facility of sport for trainers, who lead active weekends), recreational opportunities for kids (which include walking, hiking, seminars about nature and the local environmental ecosystems of the national park, how to behave, learning about animals, active kids, seminars and arranging meetings with top athletes to speak to kids about sport), faculty for sport, and biathlon school (the Slovenian ski federation host 8-10 groups for 5 days throughout the year as special training for kids). In the winter, ski clubs host events every Saturday and Sunday and there are also summer sport/recreation events for people of all ages (on Sunday's in the summer these are always run at full capacity). Additionally, in Pokljuka: Nordic walking, fitness and wellness activities are offered in summer and an 'Eskimo Village', in partnership with sports agency, is offered in winter. The winter option includes an open restaurant and bar, and two modules for overnight sleeping in an igloo, which are in high demand late-December and January during the holiday times. But given the current unpredictable climate, they have a problem when the snow arrives too late.

Pokljuka also offers additional events including teambuilding skills over two days, which involve high levels of efficiency and effectiveness, research retreats. The Oviratlon Obstacle Challenge (an obstacle course for police/military, now a popular leisure activity) attracts 2000 competitors and 2000 spectators, so draws both active/passive participation (the event in Pokljuka was held in June 2018). Other popular events held in this rural locale include cross-country skiing races such as Pokljuški marathon AS and No Border Cup (international event involving different age categories), winter triathlon event (involving running, cross-country skiing and biking), the World War II memorial race that attracts 6000 7000 people in July, and kids races (involving local schools with around 1000 kids).

Despite the event and recreational offering, the national championships for (Nordic) crosscountry skiing and biathlon occur just about every weekend for people of all different ages and competition levels. Active participants can use the infrastructure for free, with the condition (or expectation) that they purchase food/drink from their hospitality services. If the ski federation organises an outing for a private group(s) they can also use the facilities for free but must agree to purchase a predetermined amount of meals based on number of 
participants. If a group does not wish to purchase a hospitality package, they are charged $€ 90$ for 3 hours, but this option is not so common because most people come to eat as well. It benefits the centre and community when money is spent here instead of Ljubljana (the capital of Slovenia). If a large group is organised, they can receive a discount on meals.

The treks for competitors and regular sportspeople were free until 2016, as based on the European commission requirements. But since 2016, they start to charge for treks using a synchronised computer payment system used across Slovenia, this way they know who is skiing when and where in Slovenia to collect payment for trekking and use of the space, and even for parking for €4/day. Such a computerised system is useful for managing operations and logistics and holds people responsible should they damage the natural environment. This represents a system in place to ensure environmental sustainability is maintained, because in the past when it was free to use the site there were issues with people damaging the environment and local ecosystems (as people were taking strawberries, mushrooms and vegetation).

In Pokljuka, managers and planners do what they can to limit the impact of sports tourism and events on the natural environment. Having environmental policies that protect and preserve are especially crucial in mountainous areas where there is a higher chance of erosion and runoff contaminating water sources downstream in valleys and population centres. To minimise this, organisers follow strict rules to protect the environment year-round. For instance, concerning the winter triathlon, if the temperature is too warm, they are not allowed to carry out the event because this can ruin the tracks and the underlying/surrounding vegetation. During the events, when the accommodation is full, they have strict regulations on waste, and all waste must be collected (so all waste materials are not littered into the environment and disrupt local ecosystems). In recent years because of a decrease in the amount of natural snow during the autumn and winter months, in Pokljuka they dredged a lake to accumulate and store excess water to make artificial snow. This way if snowfall totals are low in November they can produce artificial snow to attract tourists, opposed to cancelling or postponing events. Whilst the snow is not natural, producing artificial snow keeps the tracks covered and this helps reduce the risk of erosion, so they can carry on with events such as the winter triathlon.

Organisers mentioned that $30 \mathrm{~cm}$ of artificial snow is needed for the WCB's $10 \mathrm{~km}$ trek. The artificial lake can collect 10,000 cubic metres of water, and it takes one cubic meter of water to produce two to three cubic metres of snow. They also make and store an additional 15,000 cubic metres of snow depots for the next winter. Again, so if there is no snow in November, then they are prepared in advance for the WCB. It was mentioned that $80 \%$ of the snow can survive the summer months, and in the case of a raining summer $70 \%$ remains (they use technology from Finland to store and keep the snow). Another advantage is the site benefits from a sponsorship contract between Triglav Insurance Company and the Slovenian Ski Federation, and the funding that comes in from this cooperation is used to maintain the sports centre and tracks. It costs $€ 60,000$ to maintain the treks per winter season; it takes four hours to clean $21 \mathrm{~km}$ of treks every evening. The Slovenian Ski Federation and Slovenian Army also cooperate closely, and this cooperation is worth around $€ 150,000$.

The offering in Pokljuka is specific to the events and activities outlined above, they do have additional offerings so to accommodate leisure guests in Pokljuka. Some wish to use the (biathlon) shooting range, but they must follow very strict requirements set by the IBU, using the 30 shooting places. In addition, because during certain times of the year the service offering is very limited, for additional guests or those there just to spectate, to keep them entertained on the centre premises they have basketball, handball and volleyball facilities open in summer. Finally, to ensure service quality and to collect and gain feedback from participants, they use an online survey which is distributed to participants in form of a link, and through the analysis of participant feedback, organiser can gain insight on participant's 
motivations to better understand how people are satisfied by the delivery.

\section{Community Involvement / Stakeholder Par- ticipation}

In all destinations it is important to try to engage and involve the local community, so that the attractions are not just commodified, commercialised and limited to tourist consumption. Local residents have much to gain from local attractions and bountiful nature. It is especially important to involve youths, through educational opportunities. Pokljuka engages the community by promoting outdoor activities, and related to the section above, they offer special pricing policy for kindergartens and schools so that they can make use of the site, nature and facilities.

Regarding the number of employees, when events are taking place, they rely on volunteers who play a vital role in ensuring the delivery runs smoothly. Volunteering represents an opportunity for young people to gain experience in the service industries and allows locals to participate-an intangible social impact that helps reinforce pride in place. During events, volunteers are involved to direct the flow of people and offer some sense of security and they cook the meals outside the hotel. This is very important for community capacity building since volunteerism enhances social capital and sport professionals are usually more focused on short-term outputs that benefit sport, rather than engaging in sustainable long-term community ventures based on common goals (Vail, 2007).

An example of quality long-term cooperation with a government stakeholder is how Centre Pokljuka cooperates with Slovenia's military forces. Military presence in the wider area of Pokljuka ensures roads are kept clear/clean from snow, contributing to year-round employment in the surrounding towns (which is an important community impact) to ensure business operations are not disrupted. Military and police forces use Pokljuka's facilities for training and events-so it can be stated that this cooperation has significant social as well as economic impacts. As for the civil sector, beyond involving volunteers, sport events are organised together with sport asso- ciations/sport clubs, who are important stakeholders in ensuring there is a sports tourism demand. This links with business operations, and because the centre in Pokljuka is known as a specialised small organisation who cater to specific sports tourists and participants. There are different types of guests, notably are the sportspeople who know costs, how long they will stay, arrive organised, and order meals on site. Ordinary guests such as visitors or spectators can be more demanding because they do not know what they want and are not aware of the service offering in such a remote locale and do not always purchase on site.

Leisure offering in Pokljuka extends beyond cross-country skiing and biathlon competitors, as many regular guests travel here for the remote fresh air, making hiking/ climbing/mountain biking plans. This offers many business opportunities to local entrepreneurs. There are numerous sports agencies in Bohinj who offer specialist services for canyoning, sport fishing, canoeing and paragliding. Because of all agencies and the hotel do not invest in facilities or gear they minimise their storage supply; they do however rent out cross-country skis. The centre in Pokljuka does not rent bikes, so people need to bring their own stuff/gear. They do create packages for people who do bring own gear (and they have a partner that they collaborate with locally that rents bikes and equipment).

With all the service offering, this was greater opportunities for locals to initiate new enterprises to support the sports tourism industry. Many rural areas (such as Gorski kotar) experience population declines because of limited opportunities, but in Slovenia in the areas surrounding Pokljuka, and into the greater Bled region, locals are benefitting from the expansion of winter and rural sports tourism opportunities and experience business yearround. This according to locals at events and those interviewed, helps reinforce a greater pride in place and the community giving residents the opportunity to participate, enhance their wellbeing and earn income from regional sports tourism and events. 


\section{Opportunities for Gorski kotar}

This section now looks at the case of Gorski kotar based on the above insight gained and observed from Pokljuka. Considering insight from Pokljuka and established sports tourism and service delivery offers in Slovenia, this section will inform destination planners and managers in Gorski kotar based on availability, offerings and the natural environment in Gorski kotar. This section addresses what Gorski kotar can gain from understandings of sports tourism service delivery, concerning infrastructure, business operations and community involvement/stakeholder participation.

\section{Infrastructure}

Currently, Gorski kotar is a rather neglected area when it comes to winter sports tourism infrastructure. Despite a long tradition of nationally recognised achievements in crosscountry skiing and biathlon, sport facilities for winter sports tourism in Gorski kotar are inadequate. Cross-country skiing infrastructure does exist in some of the town/municipalities such as Ravna Gora, Mrkopalj and Delnice. Notably, there are two important winter facilities for biathlon and cross-country skiing: Biathlon Center Zagmajna and Nordic Center Vrbovsko. One issue is these are rarely used for events or competition purposes (once or twice per year), but rather for training. Training is also ideal so long they can attract regular clients who will bring groups - to use the facilities, and to promote the area. In Delnice for instance, there is a local football stadium where it would be possible to host cross-country skiing, but not on a regular basis as the space would need to be transformed enough to host such events. The benefit that Delnice has is there are stands which would allow for viewing and thus they could attract more than just active participants, but also spectators. There are also some other small-scale ski slopes in Begovo Razdolje, Petehovac/Delnice, Čelimbaša/Mrkopalj and Rudnik/Tršće, but these are regarded as more for residents and do not have the facilities or businesses to accommodate large numbers of visitors.

Gorski kotar does offer opportunities for hunting, with shooting ranges and crosscountry ski tracks in Zagmajna (but these are rarely used). There is nothing around the track in Zagmajna (in terms of stands and facilities) and additional infrastructures necessary for biathlon would require a dedicated shooting range area. This is not in place to accommodate sport tourists now, like the other areas discussed in the previous paragraph, instead they use the facilities primarily for training. One of the challenges is different sites have different infrastructures (i.e. Zagmajna has a shooting range but not stands and facilities; whereas Delnice has stands and facilities but not the shooting facilities). There are existing hunting lodges in Gorski kotar, and a sport such as biathlon may be of interest to develop in this region given what is available to support hunters, but cross-country sking and hunting in Gorski kotar are independent of one another. Despite the long tradition, apart from natural resources, there is no developed infrastructure for biathlon, but it can be noted that cross-country skiing and hunting as leisure activities do have potential. Moreover, from a competition and events standpoint, the shooting range in Zagmajna is located in an open meadow, so while there is adequate space, there is nothing around the track in terms of the stands and facilities that exist in Pokljuka.

Figures 3 and 4 display some of the existing infrastructures in Gorski kotar for cross-country skiing and sledding, respectively. There is a multifunctional sport hall in Delnice (ice skating rink during winter) and the landscape in Gorski kotar is equipped for sports and events, but without necessary supplementary infrastructure such as hospitality premises. In addition, popular offering is also sledding. As sledding increases in popularity, tourism planners in the local authorities need to promote the events through different marketing channels, but as the image of the destination becomes synonymous with sledding, they can create a market niche. Aligned with this niche, there is a plan to build a national sledding centre in Lokve, one of the local municipalities. Such an approach has proved beneficial in Pokljuka and while the plan to build a national sledding centre in Lokve will represent a step in the right direction, the local tourism authorities, planners, managers and event organisers in Gorski kotar have much to gain when it comes to business operations and service delivery so to maximise 


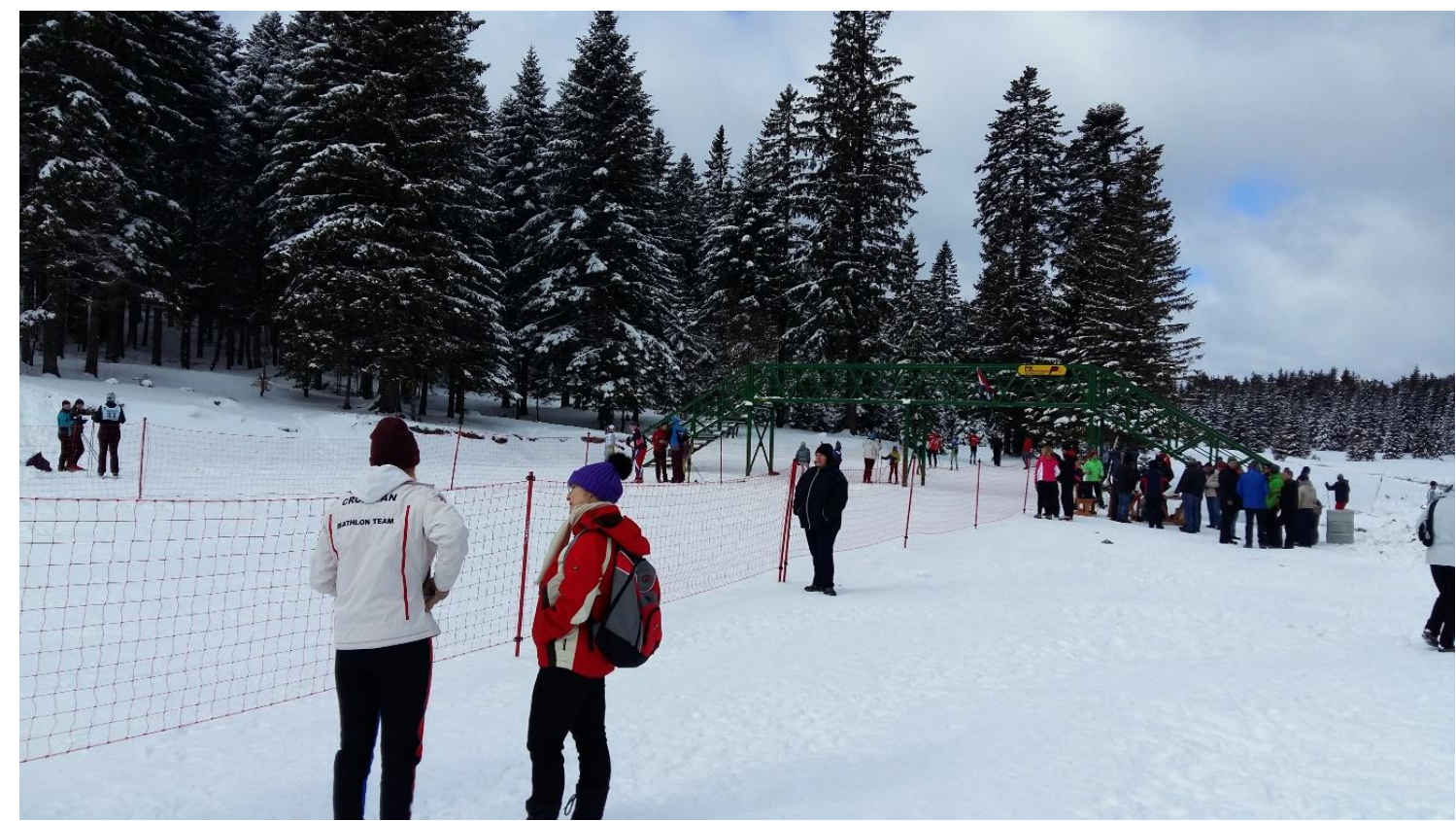

Figure 3: Finish line of the Mrkopalj Peace Memorial (cross-country race), Gorski kotar (photograph taken by $3^{\text {rd }}$ Author)
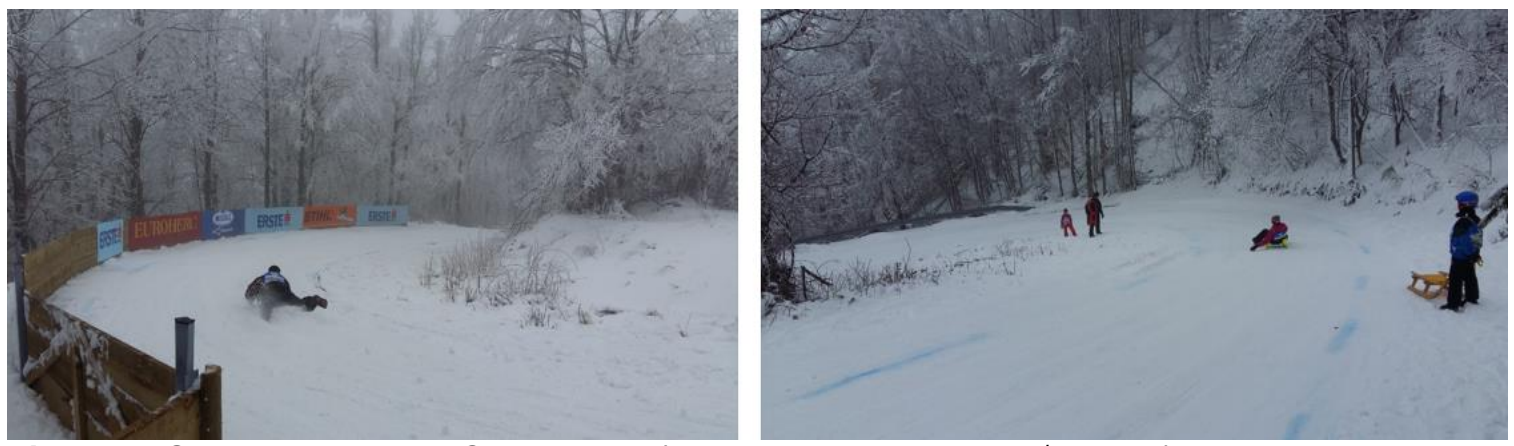

Figure 4. Sledding in Lokve, Gorski kotar (photographs taken by $3^{\text {rd }}$ Author)

the impact of the sledding centre and areas where events and activities will take place.

\section{Business operations}

Given the scale of the operation, and the remoteness, tourism planners/managers and event organisers in Gorski kotar can realise that the volume of space needed to accommodate people is not excessive. This means delivering services and events will involve maximising existing spaces, and given the local authorities are small-scale communities, much of what is needed to service events and tourists can be offered directly by local businesses-so this gives them an advantage over Pokljuka. However, based on the case of Pokljuka given their success with cross-country skiing and biathlon events, Gorski kotar does not have the capacity and natural environment to host similar events, as such events would require more specialised infrastructure (resulting in necessary investments and higher operating costs). While the funding situation in Slovenia allows Pokljuka to benefit immensely through private and public funds, therefore it is not recommended that Gorski kotar attempt to put on similar events (as it would be difficult to compete with Pokljuka). 
It would be viable to consider planning activities and events at a smaller-scale in line with the existing, operations and service delivery capacities and capabilities in the municipalities and local authorities. There is an opportunity to develop cross-country skiing in the valley areas, but for leisure and nature enthusiast purposes opposed to competitive purposes. This can bring income in the winter months and local businesses can benefit from this as a supplemental, opposed to a primary, opportunity. From a service delivery perspective, speaking back to the planned national sledding centre, for this centre to be successful and to attract tourists to Gorski kotar, insight on operations, planning and service delivery from rural Slovenia is thus important.

While places are limited in the natural environment, sites and situation management approaches need to be more transferrable. Based on what Gorski kotar has to offer, sledding, this does not require large expansive infrastructures. Most winter sledding takes place on natural trails. It used to be a popular activity, and remains so today, but there is no longer a Gorski kotar Sledding Cup which is something the local tourism authorities across Gorski kotar are trying to work on delivering as a regional event. Therefore, planners, organisers and officials in Gorski kotar can look to the service delivery associated with events in the above section to assess successful and sustained techniques. Local communities of Gorski kotar are already working on popularisation of sledding by organising various races. But a major issue with the sledding events being organised in Gorski kotar is they are of local significance and thus do not attract larger number of tourists from outside the region. Sledding is organised using ad-hoc (created) infrastructure, and marketing efforts are oriented on rather narrow target groupsdue to the improvised sledding tracks and limited additional offer. Still, the proposed creation of the mentioned national sledding centre would likely boost interest in this activity, in terms of offer and market appeal, and create a base to expand into more complex sports tourism/events offers and packages.

Ownership and management of the sporting infrastructure is the major issue in Gorski kotar.
Currently in Gorski kotar, there is one private sledding area with all related infrastructure which offers various options, but the sledding track is short and is mostly suitable for children. Other sledding places are in public and natural areas and can only be used for sledding once tracks have been created with adequate machinery. Therefore, if Gorski kotar wants to develop as a tourism-oriented region using sport and recreational activity as a driver, tourism officials need to strategically develop sledding. In terms of organising the service delivery and managing operations, they must identify roles for each service provider and designate areas making use of existing infrastructure and planning new infrastructures for events purposes or dedicated times of the year for different/multiple summer and winter activities utilising the same spaces as per the case of Pokljuka (based on their situation with cross-country skiing and biathlon in the winter and skiing on wheels in the summer).

\section{Community Involvement / Stakeholder Par- ticipation}

To reflect on the facilities and infrastructures in Pokljuka, and when we consider the natural environment and resources, Pokljuka is very similar to Gorski kotar, but an advantage that Pokljuka has is funding exists in the destination to develop it. From a funding perspective, this represents a challenge for Gorski kotar, but understanding how spaces are arranged and how participants can be mobilised, this can be creatively orchestrated in Gorski kotar given the rural road networks in the valley areas between towns. In Pokljuka the landscape is closed off from small towns and villages. Managing expansive events in Gorski kotar might involve the need to close roads (which can disrupt daily activity for locals).

However, since there is some cross-country skiing infrastructure in Ravna Gora, Mrkopalj and Delnice, no roads would need to be closed-but the amount of available space would be more limited. There is the opportunity to make use of existing infrastructures and trails in Gorski kotar to host events that consume much space and managing transportation networks would involve local planners rerouting traffic during events. Local communities in Gorski kotar could also be 
directly involved in the events as participants, observers or contribute to the service offering. One of the major restraining factors impeding the future development of winter sports/winter sports tourism is the lack of snow. Snowmaking guns could help dealing with problem, as Pokljuka found as a solution to host events in November, but it does require having a reservoir of water-which Gorski kotar does have. While it is unrealistic that private funds could be gathered to use snow preserving technology in Gorski kotar, but simpler snow depots could be considered. However, a key concern is Gorski kotar does not benefit from the same environmental lapse rate extent as Slovenia-because the heights of the mountains to not reach the same extents as in the Slovenian Alps.

Engaging with the community and stakeholders to promote outdoor activities for youth (e.g. for kindergartens and schools) is something that will need to be considered in Gorski kotar. This would generate income from school activities, and Pokljuka does this well to educate young people about the importance of nature-thus expanding their service delivery. Given the natural environment and unique ecosystems in Gorski kotar, youth educational programmes are something they could adapt to generate supplemental income (especially in the warmer months).

Whilst similarities exist in terms of where to accommodate participants and attendees, it will be useful for businesses in local authorities in Gorski kotar to seek-out collaborations with similar or related businesses in other local authorities so that they can accommodate any overflow. Arrangements benefit regular clientele so that business owners will be more aware of consistent reservations and will help with planning for meals and other offerings to cater to tourist or school groups. Moreover, they could develop specific price packages for people who bring their own gear, or this could result in a local enterprise opportunity would be to rent gear and equipment for beginners or for those traveling longer distances. Therefore, the concept of offering and delivering packages means that this can get more people involved in the local tourism industry to increase local service sector employment.
In Gorski kotar, since they are further from larger urban centres, the local restaurants will gain from any increased tourism flow because the food service offering is restricted. An issue would be if people bring their own food, because they deem restaurant costs to be too high. Restaurant owners and managers need to consider menu prices and preparing dishes that are common to the region to add to the consumer experience. In case of Pokljuka, all infrastructures have been operated by a single enterprise, and they have developed mutually useful cooperation with other private business, the local community (volunteers) and even the government sector (military presence). This is what is lacking to Gorski kotar, where locations for winter sport activities are scattered and divided between different local self-government units-without mutual cooperation and strategic planning.

Moving towards a more enabling service delivery and expanding operational opportunities in Gorski kotar can have positive impacts on the local community. A major issue is combating population decline, which is an issue not only in Gorski kotar, but other rural regions of Croatia, the Balkans and Eastern Europe. Job opportunities mean young people could decide to stay in Gorski kotar opposed to moving to larger cities (such as Rijeka and Zagreb), and the cost of living is much cheaper in rural areas, so they can maintain a close connection to their home region. Another important component of service delivery is event volunteering. Volunteering in Gorski kotar has generally been not so popular, but increasingly many people are volunteering to support sports and cultural activities or local organisations. As the events offering grows, there will likely be a need for local volunteers to get involved in event organisation. This is a chance for locals to increase local capacity building through participation, and volunteering at successful events has sociological implications in terms of reinforcing pride in place and motivating individuals to start small businesses to support a bourgeoning sports tourism/events industry in the future.

\section{Discussion: Evaluating Planning, Managing and Service Delivery Going Forward}

Kozak (2002) mentions research exploring what is happening in terms of service delivery 
or design, as a means of benchmarking, is conducted to gain practical understanding. Developing a destination that is going to be sustainable in terms of community participation, involves developing a local sense of cohesion through involvement and moving towards being more economically viable. Each are essential to assess, address and promote, and benchmarking research helps researchers identify strengths and weaknesses to promote recommendations aimed at increasing competitiveness. According to Luštický and Bína (2014) and Pike (2017), benchmarking is not only comparing resources in a destination, it is about assessing existing service offerings and looking at how events and recreational activities can be organised locally to engage the community, promote new opportunities and encourage visitors from outwith the local area. When we look at the events and supplemental experiences offered in Pokljuka, it is useful for planners in Gorski kotar to attend some of the service offerings to inspire similar activities locally.

Fuchs et al. (2002) were concerned with improving the productivity of tourism services and how said services are managed. They address several sustainability issues and found that the community in rural areas is an essential stakeholder, but more emphasis needs to be put on enterprise initiatives and staying current to maintain a particular standard of service delivery. Moreover, Fuchs et al. (2002, p. 21) suggest "core destination management activities should involve the regular benchmarking of visitor satisfaction as well as of effective resource stewardship." This will be essential for Gorski kotar going forward. As more tourists enter the region, destination planners and managers will need to evaluate customer satisfaction and determine how the destination fares in comparison to the more established destinations. This approach echoes more recent developments outlined by Herrero et al. (2017) who found that perceived quality and expectations are influenced by the awareness and reputation of the destination. In Pokljuka, the destination offer is sustained due to the WCB events offer and the history of place. Nonetheless, the development of a sustainable destination in Gorski kotar will require tourism managers and planners to leverage the positive image of Croatia, but in line with the country's desires to diversify the tourism offering.

Important for the case discussed in this research, developing tourism in destinations such as Gorski kotar is an opportunity not only to diversify the Croatian tourism offer, but also help sustain employability in more remote areas. Many people from this region seek employment opportunities in Croatia's larger urban areas or seek opportunities abroad, which is resulting in regional depopulation. But local human capital is necessary to develop a destination locally, which can be sustained through community involvement and new enterprising opportunities (Vail, 2007; Diamond, 2008). As this paper outlines, embracing and integrating good practices observed from related cases represents a chance to increase employment opportunities so that people can start or work for a business locally that is supported by visitors year-round. Gorski kotar is unique in that a mountainous destination can be utilised for sports tourism opportunities year-round, which helps combat seasonality, whereas many of the coastal destinations in Croatia see five to six months a year without tourists so many of the hotels and businesses need to close.

Indeed, local residents have much to gain from local attractions and bountiful nature, and activities need to be considered with the local community in mind to offer local social impacts and increase overall local wellbeing (see Wise, 2017; Wise \& Perić, 2017). Year-round employment can enhance social and economic sustainability locally in a destination, and observations from Slovenia show that diversifying the sports tourism offer in mountainous regions keeps people engaged year-round opposed to needing to save enough to sustain financially during the off-season. In the last few years a series of events, organised by local tourism planners and residents, have been initiated in Gorski kotar (see Đurkin \& Wise, 2018; Perić, Čuić Tanković \& Đurkin, 2017; Perić, Škorić \& Jurčević, 2016) but there is still much to do to reach Slovenian standards, which is why Slovenia is a strategic destination to benchmark planning, managing and service delivery. 
Establishing quality cooperation between all three sectors, in terms of delivering and managing sports tourism and events services, is key for future development of the region-so to maximise benefits that can be achieved through the utilisation of natural resources (Reid 2011; Đurkin \& Wise 2018) and to promote sustainable environmental, social and economic futures (Wise, 2016). This study found that cooperation-related issues currently inhibit the sustainable development of sports tourism in Gorski kotar, confirming previous research looking at potential cultural tourism in Gorski kotar (Đurkin et al., 2017) as well as in case of cooperation on joint sport projects (Perić, Đurkin \& Wise, 2016), showing that tourism planning across different offerings face issues with planning, organising and development. Additionally, when delivering sport experience to visitors in Gorski kotar, there are always important questions concerning ownership and management of the sporting infrastructure (see Đurkin \& Wise, 2018).

The fact that both destinations, Pokljuka and Gorski kotar are both within national parks, Triglav and Risnjak, respectively, offers much impetus for business activity. Tourism in environmentally sensitive and protected areas can create considerable income for adjacent communities (Mayer et al., 2010; Mayer, 2014). However, any damage to the environment can have consequences and it is important to educate people of fragile ecosystems and what disruptions it can cause (see Mulec \& Wise, 2012). Furthermore, pro-environmental behaviour among stakeholders for the benefit of sports tourism will impact Gorski kotar twofold: first, tourism has the potential to enable and encourage sustainable behaviour (Mair \& Laing, 2013); and secondly, pro-environmental behaviour is relevant to furthering tourism's sustainability (Miller, Merrilees \& Coghlan, 2015).

\section{Concluding Remarks}

Capacity development is crucial to empower local organisations and individuals to engage in the sports tourism offer, especially during initial stages when most of the efforts should be invested to develop a quality service offering and promote opportunities and activities to various target groups: children and/or young people, to families and active sports tourists. As noted in the introduction, Gorski kotar is not a suitable location for high-quality sporting infrastructures oriented to professional sportspeople. But due to its natural attractions, tradition in winter sports and vicinity between two of Croatia's larger urban centres, developing viable and sustainable sports tourism products that will have significant positive impacts on Gorski kotar's economic and social development is possible.

This study contributes to the benchmarking literature by identifying, evaluating and discussing insight on infrastructure, business operations, community involvement and stakeholder participation specific to the cases in Slovenia and Croatia presented. The consideration of evaluating best-practices by benchmarking and comparing a case in Slovenia for the purpose of helping to enhance and develop off-season winter tourism is essential given that Croatia has the highest rate of seasonality among Mediterranean destination. Many benchmarking studies are aimed at enhancing the primary or main tourism offers to see how to enhance destination strengths and competitiveness, whereas this work is concerned with benchmarking and comparing insight for the tourism industry that is a secondary product offered during the off-season so to present findings and recommendations to extend tourism in a destination (such as Croatia).

Therefore, the image fit between sporting events and destinations is proved in both theory and practice (see Hallmann \& Breuer, 2010; Kim, Kang \& Kim, 2014), and while Pokljuka built its image using the WCB brand (using the event promotion to build the host destination's brand), Gorski kotar could focus on small-scale events (sledding events in particular). In Gorski kotar, it is not the scale of the events that managers should assess when considering the case of Pokljuka, but how they manage and involve the community that founds opportunities locally and promotes activity among the community to develop a sports tourism product and develop tourism in this rural region. 
According to Pike (2017), destination planners and organisers need to seek out long-term approaches to position a destination, and this is essential in Gorski kotar as there is existing disagreements locally as to how tourism operations and event management should be organised (as addressed by Đurkin \& Wise, 2018). Such a long-term approach is an implication for future research. Ongoing research will continue to evaluate existing strengths so that competitiveness can be adequately measured, and then can sustainable planning and organisational and operational strategies can be applied based on established case examples. Also, surveying residents about their awareness of potential tourism enterprise opportunities and entrepreneurial activities will be of great importance, especially in a destination such as Gorski kotar that needs to see increased local participation to sustain employment and the local tourism industry. Therefore, future research needs to take the themes found in this study and lead these into follow-up interviews as well as survey methods to conduct data locally in destinations such as Gorski kotar to determine how the insight offered from the established benchmark (Pokljuka in Slovenia) has influenced the planning and managing of service deliver for sports tourism and events.

The implications of the findings can be used and applied to more rural and peripheral cases in destinations that are seeking to fulfil a void in a country's tourism industry and evaluate planning, managing and service delivery among the community and vested stakeholders. Furthermore, speaking back to the implications of benchmarking is the need to conduct work at this scale across very specific case studies, opposed to looking at wider trends and influences, as specifics are most important if the research is going to have local impacts and for results to lead to implementation and change locally. To do this, academics need to share work in journal such as this work to inform other researchers, but just as importantly academics then need to disseminate results locally with stakeholders. For this study, those who participated were asked to review the sections to validate the results, this helps expand the impact of the findings because stakeholders are able to gain from the development of the themes and practical recommendations offered in the analysis.

While this paper is based on descriptive analysis of data gained from site visits and conversations in both Slovenia and Croatia, it offered insight on planning and managing operations of sports tourism and events so to benchmark sports tourism offerings in Slovenia to contribute insight for ongoing research in Croatia. The case addressed in this study, the research, and subsequent discussions are especially important because Gorski kotar, Croatia is an underdeveloped tourism area with much potential. Sport, events and tourism practitioners from Gorski kotar as well as similar destinations can benefit from the findings and discussions offered throughout this paper. Specifically, this paper offered discussion and direction that is useful for tourism planners and managers in similar destinations to consider, as it presented a fieldbased approach to assess benchmark examples useful for informing service delivery and operations locally. Therefore, observing the hosting of events and meeting with destination planners and mangers in established destinations in remote locales are best suited to offer advice and insight for lesser developed or emerging destinations going forward.

\section{References}

Armenski, T., Gomezelj, D.O., Djurdjev, B., Ćurčić, N., \& Dragin, A. (2012). Tourism destination competitiveness-between two flags. Economic ResearchEkonomska istraživanja, 25(2), 485-502.

Blancas, F.J., Lozano-Oyola, M., González, M., \& Caballero, R. (2018). A dynamic sustainable tourism evaluation using multiple benchmarks. Journal of Cleaner Production, 174, 1190-1203.

Boxwell, R.J. (1994). Benchmarking for competitive advantage. New York: McGraw-Hill.

Buhalis, D., \& Laws, E. (2001). Tourism distribution channels: Patterns, practices and challenges. London: Thomson.

Caber, M., Albayrak, T., \& Matzler, K. (2012). Classification of the destination attributes in the content of competitiveness (by revi- 
sed importance-performance analysis). Journal of Vacation Marketing, 18(1), 4356.

Camp, R.C. (2006). Benchmarking: The search for industry best practices that lead to superior performance. London: Taylor \& Francis.

Cernata, L., \& Gourdon, J. (2012). Paths to success: Benchmarking cross-country sustainable tourism. Tourism Management, 33(5), 1044-1056.

Charmaz, K. (2006). Constructing grounded theory: A practical guide through qualitative analysis. London: SAGE.

Chase, K. (2011). Narrative inquiry: Still a field in the making. In Denzin, N.K., \& Lincoln, Y.S. (eds.) The SAGE handbook of qualitative research. London: SAGE, 421434.

Creswell, J.W. (2012). Qualitative inquiry and researcher design: choosing among five approaches. London: SAGE.

Croatian Bureau of Statistics (2013). Census of population, households and dwellings 2011. Zagreb: Croatian Bureau of Statistics.

Diamond, J. (2008). Capacity building in the voluntary and community sectors. Public Policy and Administration, 23, 153-166.

Domínguez Vila, T., Darcy, S., \& Alén González, E. (2015). Competing for the disability tourism market- a comparative exploration of the factors of accessible tourism competitiveness in Spain and Australia. Tourism Management, 47, 261272.

Đurkin, J., \& Wise, N. (2018). Managing community stakeholders in rural areas: Assessing the organisation of local sports events in Gorski kotar, Croatia. In Jepson, A., \& Clarke, A. (eds.) Power, construction and meaning in festivals \& events. Abingdon: Routledge.

Đurkin, J., Perić, M., \& Kljaić Šebrek, J. (2017). Addressing organisational challenges of cultural tourism in rural areas through community-based tourism model. Conference Proceedings from the 4th International Scientific Conference ToSEE, $4^{\text {th }}-6^{\text {th }}$ May 2017, Opatija, Croatia, 145-157.

Fuchs, M., Peters, M., \& Weiermair, K. (2002). Tourism sustainability through destination benchmarking indicator systems: The case of alpine tourism. Tourism Recreation Research, 27(3), 21-33.

Gajdošík, T., Gajdošíková, Z., Maráková, V., \& Flagestad, A. (2017). Destination structure revisited in view of the community and corporate model. Tourism Management Perspectives, 24, 54-63.

Hallmann, K., \& Breuer, C. (2010). Image fit between sport events and their hosting destinations from an active sport tourist perspective and its impact on future behaviour. Journal of Sport \& Tourism, 15(3), 215-237.

Harris, J. (2006). The science of research in sport and tourism: Some reflections upon the promise of the sociological imagination. Journal of Sport \& Tourism, 11(2), 153-171.

Herrero, A., San Martín, H., del Mar Garcia de Ios Salmones, M., \& Collado, J. (2017). Examining the hierarchy of destination brands and the chain of effects between brand equity dimensions. Journal of Destination Marketing \& Management, 6(4), 353-362.

João Carneiro, M., Breda, Z., \& Cordeiro, C. (2016). Sports tourism development and destination sustainability: the case of the coastal area of the Aveiro region, Portugal. Journal of Sport \& Tourism, 20(3/4), 305-334.

Khazai, B., Mahdavian, F., \& Platt, S. (2018). Tourism Recovery Scorecard (TOURS) Benchmarking and monitoring progress on disaster recovery in tourism destinations. International Journal of Disaster Risk Reduction, 27, 75-84.

Kim, J., Kang, J.H., \& Kim, Y-K. (2014). Impact of mega sport events on destination image and country image. Sport Marketing Quarterly, 23(3), 161-175.

Kozak, M. (2002). Destination benchmarking. Annals of Tourism Research, 29(2), 497519.

Kozak, M. (2003). Destination benchmarking: Concepts, practices and operations. London: CABI.

Kozak, M. (2004). Introducing destination benchmarking: A conceptual approach. Journal of Hospitality \& Tourism Research, 28, 281-297. 
Kozak, M., \& Baloglu, S. (2011). Managing and marketing tourist destinations: Strategies to gain a competitive edge. London: Routledge.

Levy, D. (2015). Discovering grounded theories for social justice. In Johnson, C.W., \& Parry, D.C. (eds.) Fostering social justice through qualitative inquiry. Walnut Creek: CA: Left Coast, 71-99.

Lundmark, L., Muller, D.K. (2010). The supply of nature-based tourism activities in Sweden. Tourism, 58(4), 379-393.

Luštický, M., \& Bína, V. (2014). Application of fuzzy benchmarking approach for strategic planning of tourism destination. Journal of Quality Assurance in Hospitality \& Tourism, 15(4), 327-355.

Mair, J., \& Laing, J.H. (2013). Encouraging proenvironmental behaviour: the role of sustainability-focused events. Journal of Sustainable Tourism, 21(8), 1113-1128.

Mayer, M. (2014). Can nature-based tourism benefits compensate for the costs of national parks? A study of the Bavarian Forest National Park, Germany. Journal of Sustainable Tourism, 22(4), 561-583.

Mayer, M., Müller, M., Woltering, M., Arnegger, J., \& Job, H. (2010). The economic impact of tourism in six German national parks. Landscape and Urban Planning, 97(2), 73-82.

Miller, D., Merrilees, B., \& Coghlan, A. (2015). Sustainable urban tourism: understanding and developing visitor pro-environmental behaviours. Journal of Sustainable Tourism, 23(1), 26-46.

Ministry of Tourism (Ministarstvo turizma Republike Hrvatske) (2018). Turistički promet od siječnja do prosinca 2017. godine [Tourist traffic January-December 2017]. URL: http://mint.hr/UserDocsIma ges//AA_2018_c-dokumenti//180219 stat_I_XII-017.pdf (Accessed 2.6.2017).

Moriarty, J.P. (2011) A theory of benchmarking. Benchmarking: An International Journal, 18(4), 588-611.

Mulec, I., \& Wise, N. (2013). Indicating the competitiveness of Serbia's Vojvodina Region as an emerging tourism destination. Tourism Management Perspectives, 8, 68-79.

Mulec, I., \& Wise, N. (2012). Strategic guidelines for the potential geotourism destination Titel Loess Plateau (Vojvodina, Serbia). Geoheritage 4(3), 213-220.

Müller, H., \& Berger, P. (2012). Benchmarking for destination management organizations: the case of Swiss cities and Alpine destination management. Tourism Review, 67(4), 26-39.

Oses, N., Gerrikagoitia, J.K., \& Alzua, A. (2016). Monitoring and benchmarking the performance of a destination's hotel industry: the case study of Bilbao in 2014. Tourism Management Perspectives, 19, 48-60.

Perić, M., Čuić Tanković, A., \& Đurkin, J. (2017). Role of brand personality traits in creating an umbrella brand for small-scale events: Case of Gorski kotar, Croatia. Društvena istraživanja: časopis za opća društvena pitanja, 26(4), 561-581.

Perić, M., Đurkin, J., \& Wise, N. (2016). Leveraging small-scale sport events: challenges of organising, delivering and managing sustainable outcomes in rural communities, the case of Gorski kotar, Croatia. Sustainability, 8, 1337.

Perić, M., Škorić, S., \& Jurčević, V. (2016). Sport tourism supply in Gorski kotar (Croatia) - analysis and possible recommendations for providers. Acta Turistica, 28(1), 49-71.

Perić, M., \& Wise, N. (2015). Understanding the delivery of experience: conceptualising business models and sports tourism, assessing two case studies in Istria, Croatia. Local Economy, 30(8), 1000-1016.

Perić, M., Wise, N., \& Dragičević, D. (2017). Suggesting a service research agenda in sport tourism: working experience(s) into business models. Sport, Business and Management: an International Journal, 7(1), 58-76.

Pike, S. (2017). Destination positioning and temporality: Tracking relative strengths and weaknesses over time. Journal of Hospitality and Tourism Management, 31, 126-133.

Quaranta, G., Citro, E., \& Salvia, R. (2016). Economic and social sustainable synergies to promote innovations in rural tourism and local development. Sustainability, 8, 668. 
Reid, S. (2011). Event stakeholder management: Developing sustainable rural event practices. International Journal of Event and Festival Management, 2, 20-36.

Sainaghi, R., \& Baggio, R. (2017). Complexity traits and dynamics of tourism destinations. Tourism Management, 63, 368-382.

Slovenian Tourist Board (2018). 2017 Tourism in numbers. Ljubljana: Slovenian Tourist Board

Spirou, C. (2011). Urban tourism and urban change: Cities in a global economy. London: Routledge.

Warburton, D. (Ed.) (2009). Community and sustainable development: Participation in the future. London: Earthscan.

Vail, S.E. (2007). Community development and sport participation. Journal of Sport Management, 21, 571-596.

Wise, N. (2011). Post-War tourism and the imaginative geographies of Bosnia and Herzegovina, and Croatia. European Journal of Tourism Research, 4(1), 5-24.

Wise, N. (2016). Outlining triple bottom line contexts in urban tourism regeneration. Cities, 53, 30-34.

Wise, N. (2017). Editorial, Local community and local economy: place, policies and power at the Micro-Scale. Local Economy, 32(7), 595-600.

Wise, N., Aquilino, L., \& Armenski, T. (2018). Preparing for Matera 2019: local resident participation in research and perceptions of destination competitiveness. In Clark, J., \& Wise, N. (eds.) Urban Renewal, community and participation: Theory, policy and practice. Berlin: Springer.

Wise, N., \& Harris, J. (eds) (2017). Sport, events tourism and regeneration. London: Routledge.

Wise, N., Mulec, I., \& Armenski, T. (2017). Towards a new local tourism economy: understanding sense of community, social impacts and potential enterprise opportunities in Podgrađe Bač, Vojvodina, Serbia. Local Economy, 32(7), 656-677.

Wise, N., \& Perić, M. (2017). Sports tourism, regeneration and social impacts: new opportunities and directions for research, the case of Medulin, Croatia. In Bellini, N., \& Pasquinelli, C. (eds.) Tourism in the city: Towards and integrative agenda on urban tourism. Berlin: Springer Vieweg, 311-320.

Woodside, A.G. (2016). Participant observation research in organizational behaviour. In Woodside, A.G. (ed.) Case study research. Bingley: Emerald, 331-352.

Xiang, Z., Kothari, T., Hu, C., \& Fesenmaier, D.R. (2007). Benchmarking as a strategic tool for destination management organizations: a proposed framework. Journal of Travel \& Tourism Marketing, 22(1), 81-93.

Yin, R.K. (2009). Case study research: Design and methods. London: Sage. 